\title{
Analyzing Internal Stakeholders' Salience in Product Development
}

\author{
Tuomo Kinnunen*, Aki Aapaoja, Harri Haapasalo \\ Industrial Engineering and Management, University of Oulu, Oulu, Finland \\ Email: ${ }^{*}$ tuomo.kinnunen@oulu.fi, aki.aapaoja@oulu.fi, harri.haapasalo@oulu.fi
}

Received 20 March 2014; revised 20 April 2014; accepted 27 April 2014

Copyright (C) 2014 by authors and Scientific Research Publishing Inc.

This work is licensed under the Creative Commons Attribution International License (CC BY). http://creativecommons.org/licenses/by/4.0/

(c) (i) Open Access

\begin{abstract}
Many companies apply Design for $\mathrm{X}$ principles to consider production and product lifecycle cost implications in the early phase of product development. In these companies, representatives of different Design for $\mathrm{X}$ disciplines form a specific group of internal stakeholders. This single case study constructs a stakeholder salience assessment framework and uses the framework to analyze internal stakeholders' salience in product development in the case company. As the main result, the compared stakeholders are sequenced and their relative saliences are valued and visualized. In that single case, product management representatives perceived Design for Testing as clearly the most salient stakeholder being four times more salient than Design for Packaging. The framework and assessment procedure are applicable to use in other contexts and companies. This study exemplifies usage of the framework but the results are not generalizable. After salience assessment a company may take corrective actions to increase or decrease the salience of specific stakeholder group, to disband an internal stakeholder group, to consolidate some stakeholder groups together, or to segregate a Design for $\mathrm{X}$ group into several groups. The novel approach of this study is to apply the stakeholder salience assessment framework in product development context.
\end{abstract}

\section{Keywords}

Design for X, DFX, Stakeholder, Salience, Product Development, Product Management, Assessment, Analytic Hierarchy Process, AHP

\section{Introduction}

To succeed, companies must create products which meet customer needs and fulfill a multitude of varying re-

*Corresponding author. 
quirements [1]. These requirements often originate from a large number of stakeholders with various interests. A specific group of internal stakeholders may be formed from representatives of Design for X (DFX) disciplines. These DFX stakeholders work to incorporate relevant product lifecycle aspects in product development [2]. The generic aim of DFX is to ease the product flow in downstream operations and to reduce the total lifecycle cost of a product [3]. As even the majority of product lifecycle costs are dictated in the early design phase, DFX principles and tools are adopted in many companies to consider the cost implications of design decisions [4].

A stakeholder is any group or individual who can affect or is affected by a product [5]. Different stakeholders vary in importance and in authority, in other words in salience, during product development. Salience is a dynamic stakeholder characteristic which varies according to time, the lifecycle phase and a product type. Mitchell et al. divide salience into three attributes: power, legitimacy and urgency [6]. For successful product development and efficient delivery, it is essential to manage stakeholders depending on their salience. Product managers play a key role in determining the salience of stakeholders since they have to balance limited time and resources for development with high expectations for the product in terms of cost, performance and quality [7].

The literature includes extensive studies on how to develop products and the critical success factors for product development [1] [8]. However, relatively few attempts have addressed the issue of who really matters in product development or what is the weight of different stakeholders. The number of stakeholders can be high and naming all kinds of stakeholders can be ending on a long list [9] [10]. However, the primary stakeholders cannot be more than ten, otherwise it will be impossible to operate and deal with requirements set by these stakeholders (see e.g. [11] [12]). Stakeholder management has recently been an issue in project management research [13]-[15]. We aim to extend this issue to the product development research field by providing a practical example of analyzing the saliences of internal stakeholders.

Our objective is to create and test a framework for defining and analyzing DFX stakeholders' saliences in product development. The objective is further defined by the following research questions:

1) How can stakeholder salience be analyzed in product development?

2) How does salience of internal stakeholders vary in the case company?

To reach the objective an industrial case study was designed and conducted. During the study design, the stakeholder salience model [6] was adapted into analytic hierarchy process (AHP). The first research question is answered by setting up the AHP salience assessment framework for product development context in a case company. Then the second research question is answered by testing the AHP salience assessment framework for determining the salience of the stakeholders. This empirical part of the study was conducted in the case company which develops ICT system products. The case study aimed at analyzing the current state of the DFX stakeholders' salience in the case company. The study is both descriptive and normative.

To begin, this study reviews the current literature of stakeholder management and design for $\mathrm{X}$. Then the study methodology is presented. Next the different types of stakeholders are named by the case. After this, the empirical case and the results are presented and analyzed. Finally, results are discussed with managerial implications and our conclusions are drawn.

\section{Literature Study}

Product development in the context of large scale ICT systems includes several participating groups, each with their own needs and requirements. An important issue for the product development is identifying and analyzing stakeholders who can have an influence over the design and development outcomes and decisions [16]. In general, stakeholders are "people or groups who are directly or indirectly affected by a project, as well as those who may have interests in a project and/or the ability to influence its outcome, either positively or negatively" [17]. Internal stakeholders, as understood in this study, are positioned and operating within the company in question. Influence can be assessed through the stakeholder identification and salience model.

\subsection{Stakeholder Salience}

Stakeholder salience describes "the degree to which managers give priority to competing stakeholder claims" [6]. Thus, the more salient stakeholder the more management attention is paid. Stakeholder salience is sum of three individual attributes: power, legitimacy and urgency. The number of attributes that a stakeholder has is directly related to the salience and the degree to which managers give priority to the stakeholder claims [18]. Saliences of stakeholders are varying during product development and therefore it means that some stakeholders 
can try shape their salience attributes in order to get their voice heard [6]. External stakeholders are those who engage different kind of activities to shape their salience [13].

The first attribute, power, defines probability that one stakeholder within a social relationship is in a position to carry out his own will despite resistance. This means that stakeholder A can get stakeholder B to do something that B would not otherwise have done [6]. The type of resources used to exercise power is also explaining the bases of power [18]. The base of power can be coercive, utilitarian or normative. Coercive is based on the physical resources of force, violence or restraint. Utilitarian power is based on material or financial resources. Normative power is based on symbolic resources [19]. Because power can occur in many forms, the structure of the development network and the position of the stakeholders in a network must be taken into account.

Legitimacy is "a generalized perception or assumption that the actions of an entity are desirable, proper or appropriate within some socially constructed system of norms, values, beliefs and definitions" [20]. Usually product managers are more willing to pay attention to stakeholders whose claims they perceive to be legitimate [18]. Legitimacy can stem from individuals, organizations or society. However, even if a stakeholder has a legitimate claim, it may not be salient in the eyes of the product manager unless the stakeholder has power to enforce the claim [6]. For example, contractual relationships with the product increase the power and therefore stakeholders that do not have a contractual relationship, are often neglected [13]. This can be seen that customer and sales representatives as well as production representatives overrule those not directly involved to the product, such as representatives of environmental issues.

The last attribute is the urgency of the stakeholders' request. Urgency is "the degree to which stakeholder claims call for immediate attention" [6] and it is based on two features: criticality and time sensitivity. The criticality refers to the importance of the claim to the stakeholder and time sensitivity is the degree to which managerial delay in attending to the claim or relationship is unacceptable to the stakeholder [6] [13]. Basically, urgency can be understood as an interest of the stakeholder. In the ICT system development, the negative consequences that refer to the product feasibility and implementation seem to be important factors that increase the urgency of the claims [17]. Despite the urgency is not as concrete attribute than power and legitimacy, it does not decrease the importance of it. Urgency determines the dynamics of stakeholder salience and the interactions between stakeholders [6]. Salience attributes are illustrated in Figure 1 as the basis for the assessment framework building in this study.

\subsection{Design for $\mathrm{X}$}

Design for X (DFX) approaches product design and development from certain production and product lifecycle aspects, such as assembly, manufacturability and environment [2]. DFX presents a systematic approach to implement concurrent engineering [10] [12] [21]. The generic aim of DFX is to ease the product flow in downstream operations and to reduce the total lifecycle cost of a product [3]. Correspondingly, design cost tends to increase as a result of DFX and that presents the trade-off for potential benefits in product costs [22].

In a typical business context, design for $\mathrm{X}$ is focusing on five to nine relevant aspects at a time to improve product design in respect of these aspects [11]. DFX concept has emerged in Design for Manufacturing (DFM) and Design for Assembly (DFA) fields [3] [23]. During last two decades DFX has evolved to cover tens of varying aspects, tools and methods and that evolution has widened DFX from the original product scope into system and eco-system scopes [22]. However, the concept of DFX is ambiguous and the application fields of DFX

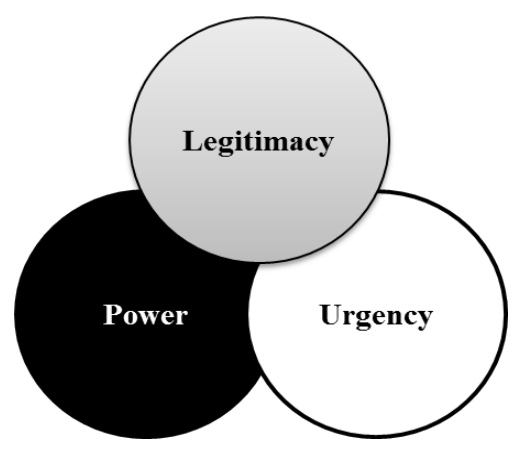

Figure 1. Salience attributes. 
are diverged [10]. Next most established and mature DFX disciplines in product scope are briefly studied to clarify the field. In addition, there are plenty of others emerging disciplines, such as DFS (Design for Services) and DFSC (Design for Supply Chain), which are recognized in literature are not that established practices in general [3] [12] [22].

Design for assembly. DFA is one of the two original DFX aspects which aim product design that is economically assembled by the most appropriate assembly system [3] [23]. Designers pay attention to the assemblyrelated aspects, such as fastening methods, symmetry of the parts, size of the parts and angles of insertion. DFA methodology aims to simplify the design by minifying number of parts, and easing their insertion [23].

Design for Manufacturing. DFM as another original DFX aspect focuses on manufacturing process capabilities and cost estimation of parts when designing product attributes [3] [12]. DFM, together with DFA, makes the product easier to manufacture and with lower costs [3].

Design for packaging. DFP ought to establish an effective trade-off among the three crucial factors of packaging: physical dimensions, package strength and package shape [21]. The main function of packaging is purely technical so that it helps to protect, maintain and minimize the waste of a product while adding convenience and providing the customers with essential product information [24].

\subsection{Theoretical Framework}

Design and development of systemic products is characterized by the involvement of multiple stakeholders from the wide variety of fields. Stakeholder networks can often be extremely complex, particularly in large scale systems where the number of different stakeholders can be huge [25]. In products, many different interest and requests must be considered and therefore an important issue for the product management is to identify and analyze stakeholders who can have an influence over decisions [6] [15] and an impact on development performance.

Stakeholder analyzing is crucial for the success of the product, but effective stakeholder identification and management is a challenging task. In addition, stakeholder salience may be varying during a project and thus stakeholder management is a continuous process. Mitchell et al. [6] have stated that power (P) by itself does not guarantee high salience, but it gains authority through legitimacy $(\mathrm{L})$ and it gains exercise through urgency $(\mathrm{U})$. In addition, legitimacy gains its rights through power and voice. Common proposal is that power and legitimacy are the core attributes and are together forming an authority, but urgency determines the criticalness and timesensitiveness of claims and salience. More specifically, stakeholders can be divided into four classes based on how many of the salience attributes they possess [6]. The classification and generic description are presented in Table 1.

\section{Methods}

Case study was selected to the primary research method to assess DFX stakeholders' salience in design and

Table 1. Stakeholder classification (combined from [6]).

\begin{tabular}{|c|c|c|c|}
\hline \multicolumn{2}{|c|}{$\begin{array}{l}\text { Stakeholder descriptive } \\
\text { classification }\end{array}$} & Description & \multirow{2}{*}{$\begin{array}{c}\begin{array}{c}\text { Possessing salience } \\
\text { attributes }\end{array} \\
\text { P, L, U }\end{array}$} \\
\hline $\begin{array}{l}\text { Definitive stakeholder } \\
\text { "Highly salient" }\end{array}$ & & $\begin{array}{l}\text {... managers' have a clear and immediate mandate to } \\
\text { attend to and give priority to that stakeholder's claim }\end{array}$ & \\
\hline \multirow{3}{*}{$\begin{array}{l}\text { Expectant stakeholders } \\
\text { "Moderately salient" }\end{array}$} & Dominant stakeholder & $\begin{array}{l}\text {...'s influence in the firm is assured due to having } \\
\text { legitimate claims and ability to act on these claims }\end{array}$ & $\mathrm{P}, \mathrm{L}$ \\
\hline & Dependent stakeholder & $\begin{array}{l}\text {...have urgent legitimate claims but depend upon } \\
\text { others for the power to carry out their will }\end{array}$ & $\mathrm{L}, \mathrm{U}$ \\
\hline & Dangerous stakeholder & ... will be coercive and possibly violent & $\mathrm{P}, \mathrm{U}$ \\
\hline \multirow{3}{*}{$\begin{array}{l}\text { Latent stakeholders } \\
\text { "Lowly salient" }\end{array}$} & Dormant stakeholder & ... have a little or no interaction with the firm & $\mathrm{P}$ (power) \\
\hline & Discretionary stakeholder & ... have no power to influence and no urgent claims & L (legitimacy) \\
\hline & Demanding stakeholder & ... "mosquitoes buzzing in the ears" & U (urgengy) \\
\hline $\begin{array}{l}\text { Non-stakeholder } \\
\text { "Not salient" }\end{array}$ & & ... potential stakeholder or not stakeholder at all & - \\
\hline
\end{tabular}


development of complex ICT products in the case company. This method is preferred when the focus is in a contemporary phenomenon within real-life context where the researcher has little control over events [26]. Furthermore, single case strategy is used in order to cover company specific DFX context and meet the testing objective. Research process is illustrated below in the Figure 2.

The case company is a large global ICT system provider. The case company has applied DFX concept over a decade and they have globally defined and organized DFX disciplines. Based on the case company documentation and discussion with a management representative, following seven DFX stakeholders were selected as most relevant for this case study: Design for Testing (DFT), Design for Assembly (DFA), Design for Packaging (DFP), Design for Serviceability (DFS), Design for Supply Management (DFSM), Design for Demand/Supply chain (DFDS) and Design for Environment (DFE). All of these are internal stakeholders for product development, although DFE, for example, represents typically bunch of external stakeholders affecting to company.

\subsection{Case Study Design}

Salience is defined as "the degree to which managers give priority to competing stakeholder claims" [6]. Thus, this study considers salience by approaching product management representatives in the case company and studying their perceptions to the DFX stakeholders. Stakeholders' salience is depending on the distribution of power (P), legitimacy (L) and urgency (U) that each stakeholder possesses. In the interviews, product managers were asked to compare each DFX stakeholder against each other by relative scale [27], see Table 2. Comparison matrixes (size $7 \times 7$ in this study) were established for pairwise comparisons. The purpose of the pairwise comparisons was to put the DFX stakeholders in order of importance based on their saliences.

\subsection{Data Collection and Analysis Procedure}

The data was collected by interviewing 12 product management representatives and asking them to compare DFX stakeholders. Every respondent fulfilled three pairwise comparisons matrixes, one for each salience attribute. Empirical studies [15] [29] indicate that the attributes were roughly of equal importance, but power is little more important than the others. In this study, the salience was calculated weights as power $(P=0.4)$, legitimacy $(\mathrm{L}=0.3)$ and urgency $(\mathrm{U}=0.3)$ according to [15]. The prioritization of stakeholders was calculated using a weighted average of those three priority vectors.

When all the pair wise comparisons are made, the priority vectors (eigenvectors) can be calculated as follows: each element of the matrix is divided by its column total and then priority vector can be obtained by finding the row averages. After that the consistency of comparison is determined by using the eigenvalue $\left(\lambda_{\max }\right)$ to calculate the consistency index $(\mathrm{CI}), \mathrm{CI}=\left(\lambda_{\max }-\mathrm{n}\right) /(\mathrm{n}-1)$. After that, the consistency ratio $(\mathrm{CR})$ can be calculated by dividing the $\mathrm{CI}$ with an appropriate value of random index (RI), $\mathrm{CR}=\mathrm{CI} / \mathrm{RI}$, and in the case of $7 \times 7$

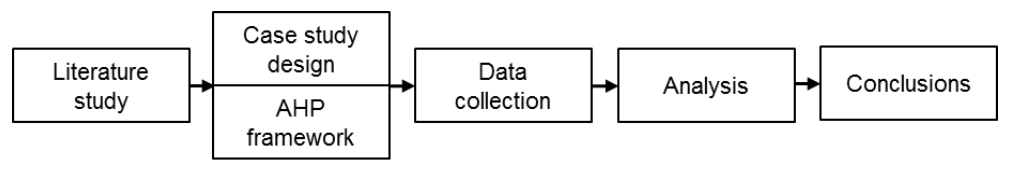

Figure 2. The research process.

Table 2. Example of relative scale used for power assessment.

1 If stakeholder $\mathrm{A}$ has equal power in relation to $\mathrm{B}$

3 If stakeholder $\mathrm{A}$ has a bit more power than B

5 If stakeholder A has essentially more power than B

7 If A has substantially more power compared to B

9 If A has absolutely higher power in relation to B

If $\mathrm{B}$ has more power compared to $\mathrm{A}$, use the inverses $(1 / 2 \cdots 1 / 9)$

Numbers 2, 4, 6, 8 and 1/2, 1/4, 1/6 and 1/8 represent intermediate values in the scale

The inverse values were automatically assigned in each pairwise comparison [27] [28]. 
matrix RI = 1.32 [28]. If CR does not exceed 0.10, it is acceptable, but if it is more than that, the judgment matrix is inconsistent. Then it should be reviewed and improved [27] [28].

\section{Results and Analysis}

As a main result, the total salience of the DFX stakeholders is presented in Table 3, where the consistency ratio (CR) is presented as well.

Product managers in the case company perceive DFT as the most salient DFX stakeholder for product development while DFP is experienced as the least salient stakeholder. The salience of DFT is four- to fivefold as compared to DFP which means essentially higher salience by Saaty's [27] comparison scale. The rest of DFX stakeholders have moderately more salience than DFP but moderately less salience than DFT. DFA is the second most salient DFX stakeholder followed by DFE and DFS. However, salience differences among these five middle DFX stakeholders are not significant and the results are more suggestive in this respect. The consistency ratio is near to the limit (0.1) meaning that data includes acceptable amount of inconsistencies. Previous AHP studies indicate that when the amount of compared factors exceeds five, CR tends to rise over the limit [30] [31]. For more detailed analysis, the results are presented against each salience attribute in Table 4.

Common fact is that most salient stakeholder for any market-driven product development is customer. Customer can be seen as a definitive stakeholder whose requirements must be identified and perceived by product management for new product success [32]. In case of complex ICT products, the requirements of internal stakeholders must be perceived too to avoid developing fuzzy offering which results problems in operations, such as testing and after sales services [33]. The results illustrated in Figure 3 show an example how product managers perceive the salience internal stakeholders in product development.

The stakeholders are briefly characterized below using the classification presented earlier in Table 1.

Design for Testing. DFT has the highest urgency and power and second highest legitimacy among DFX stakeholders. DFT is experienced almost as a definitive stakeholder and thus, comparable to customer. DFT requirements are likely to be acknowledged and attended to by product management.

Design for Assembly. DFA with second highest urgency and power can be characterized as a demanding or even a "dangerous" stakeholder for product development. DFA may present coercive requirements which, if ignored, could violate product development.

Table 3. Stakeholders' salience in product development from product management viewpoint.

\begin{tabular}{cc}
\hline Stakeholder & Salience \\
\hline Design for testing & 23.4 \\
Design for assembly & 17.8 \\
Design for services & 14.7 \\
Design for environment & 13.8 \\
Design for supply management & 12.4 \\
Design for demand/supply chain & 11.9 \\
Design for packaging & 6.0 \\
Consistency ratio CR & 0.099 \\
\hline
\end{tabular}

\begin{tabular}{|c|c|c|c|c|c|c|c|c|c|}
\hline \multirow{2}{*}{ Salience attribute } & \multicolumn{7}{|c|}{ DFX discipline } & \multirow{2}{*}{ Accepted responses } & \multirow{2}{*}{ CR } \\
\hline & DFT & DFA & DFS & DFE & DFSM & DFSC & DFP & & \\
\hline Legitimacy & 0.200 & 0.135 & 0.159 & 0.243 & 0.085 & 0.117 & 0.062 & $\mathrm{~N}=11$ & 0.096 \\
\hline Urgency & 0.237 & 0.215 & 0.135 & 0.062 & 0.149 & 0.147 & 0.056 & $\mathrm{~N}=11$ & 0.096 \\
\hline Power & 0.257 & 0.183 & 0.147 & 0.116 & 0.134 & 0.101 & 0.062 & $\mathrm{~N}=10$ & 0.105 \\
\hline
\end{tabular}




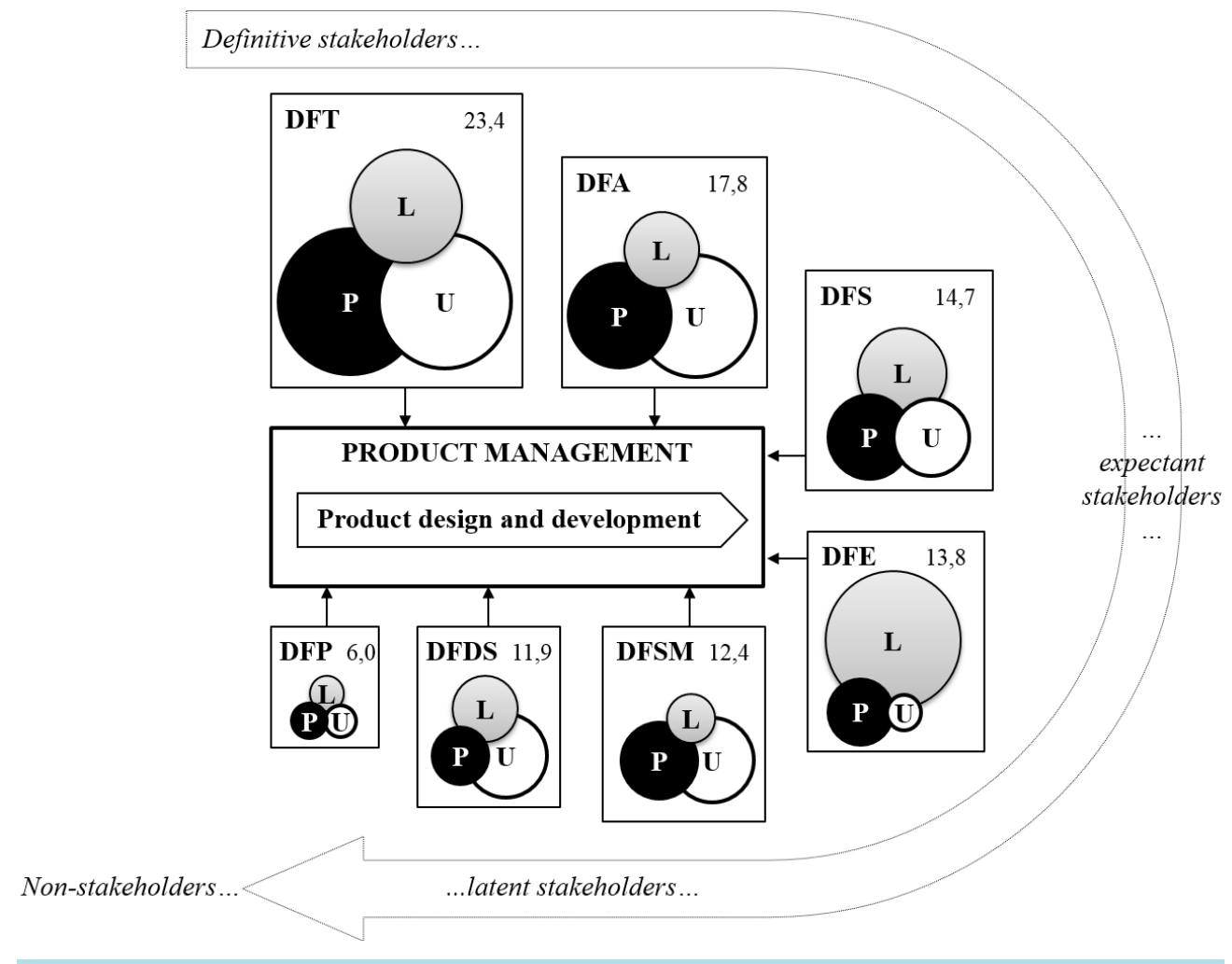

Figure 3. DFX stakeholders' salience in product development in this case.

Design for Services. DFS has third highest legitimacy and power indicating that it could be a dominant stakeholder. They may expect and receive much of product managers' attention and their requirements matters to product management.

Design for Environment. DFE has the highest legitimacy and average level power but low level urgency. DFE legitimate standing as perceived by product management may be explained by the case company's strategic emphasis on the environmental sustainability. DFE can be characterized as a discretionary stakeholder who may not pressure product management. DFE requirements are not typically highly prioritized unless they cannot gain more power e.g. from customer.

Design for Supply Management. DFSM has a similar profile as DFA but less salience. DFSM may also present coercive requirements which, if ignored, could violate product development.

Design for Demand/Supply chain. DFSC has average level urgency and low level of legitimacy and power. Thus they could be characterized as a demanding or dependent stakeholder. DFSC may need the power of other stakeholders to get their requirements highly prioritized.

Design for Packaging. DFP has relatively low salience and it can be seen almost as a non-stakeholder for product management. Certainly their requirements are likely to be passed over by product management, or they do not need a much management attention and priority. DFP may be more salient in designer level or to certain volume products.

\section{Discussion}

No organization is an island and successful product development usually requires the interaction with several stakeholders, both internal and external. A lack of understanding of the interest groups, their salience and potential to influence during the product lifecycle is a major challenge. To achieve product success, it is essential to understand both the objectives of stakeholders and the means through which their interest can affect the design and development [18].

Stakeholder salience is defined through power, legitimacy and urgency. The importance of different stakeholders depends on the possession of stakeholder attributes. Stakeholders that product management perceives to 
have high salience are usually noticed and listened more carefully than those who do not possess salience [6]. Low salience does not mean that stakeholder requirements are not listened to, but the execution of those is completely a different thing. Usually, requirements that are easy to adapt and can have a positive impact on a product and development performance are paid attention to.

DFX stakeholders are typically representatives of production and product lifecycle functions. They gather and hold empirical design knowledge based on impacts of earlier designed and delivered products. Using that knowledge, DFX stakeholders aim to formulate design guidelines and principles as well as requirements to improve new product design and development. As the results of this study show, there are differences among the DFX stakeholders and their actual saliences in product management level. The reasons of differences are not studied in this paper and this leaves room for interpretation in the company-wide and for further studies by academics.

\section{Practical Implications}

During the development stakeholders are stating different kind of needs, design rules, guidelines, wishes and suggestions. In order to maximize the overall product value and outcome with resources available, product management must prioritize those. The requirements coming from customers are often prioritized more important than those coming from the internal stakeholders. However, managers may prioritize internal stakeholders' requirements very differently.

Stakeholder management can be made easier and more systematic through the early involvement of stakeholders, lifecycle perspective, systematic management process and proactive behavior [17]. However, this practical case study shows that despite the efforts made for DFX early involvement to product development, there may be notable differences between DFXs. Because of different roles and responsibilities, stakeholders are not equal to each other. Therefore stakeholders should not be handled as a one crowd but they should be divided into groups that reflect stakeholders' roles better. Then requirements and stakeholders can be managed more efficiently and systematically.

Business and customer needs as well as companies' design and production capabilities are evolving. This evolution may, in turn, affect to potential groups and sub-groups of internal stakeholders. The salience assessment framework utilized in this study may help to recognize the shifts happened in management perceptions towards internal stakeholders. After salience assessment a company may take corrective actions to increase or decrease salience of specific stakeholder group, or even disband an internal stakeholder group. In addition, a company may consolidate some stakeholder groups together, or segregate a group into several groups. It is always topical question for companies applying DFX methods that which are the relevant Xs and how optimize the trade-offs between design cost, lifecycle cost and product value. Ideally, there might be only one integrated DFX stakeholder which could cover the full spectrum of the product lifecycle and resolve conflicts between internal stakeholders before guiding development [22]. In practice, companies may continue to focus on maintaining amount of DFX stakeholder groups manageable at a time to avoid unnecessary hassling [11].

\section{Conclusions}

This industrial case study constructs an AHP based framework for assessing stakeholders' salience in product development. A highly salient stakeholder, by definition, has power, legitimacy and urgency in their claims. The usage of the framework is exemplified by studying a single case of DFX stakeholders' saliences in a global ICT system provider's product development. The case study presents the utility and limitations of AHP for studying stakeholder saliences.

As the main result the compared stakeholders are sequenced and their relative saliences are valued and visualized. In that single case, DFT was perceived as clearly the most salient stakeholder and DFP was perceived as clearly the least salient stakeholder by product management of the case company. Thus, DFT can be defined almost as a definitive stakeholder who claims managers have a clear and immediate mandate to attend to and give priority. In turn, DFP seems to be a latent stakeholder whose claims are not easily attended by managers. The difference between these DFX disciplines is significant, or essential in the relative scale. However, except DFP, saliences among all the DFX groups in the case company are relatively indifferent.

In this paper, the main focus has been in the nature of stakeholder management in the stakeholder salience model [6] and case company's DFX organization. Stakeholder salience is built on the attributes of power, legitimacy and urgency. The model suggests that all of the salient stakeholders matter. After salience assessment a 
company may take corrective actions to increase or decrease salience of specific stakeholder group, to disband an internal stakeholder group, to consolidate some stakeholder groups together, or to segregate a DFX group into several groups. The novel approach of this study is to apply stakeholder salience assessment framework in product development context.

\section{Limitations and Further Research}

The case makes generalization possible mainly in analytical sense, not in statistical sense. As result of AHP, stakeholder saliences are described in a relative scale, not in absolute measures. This must be considered when interpreting the results.

Our study focuses on DFX stakeholders' salience perceived by product management. The same issue could be studied in product engineering level. Potential future research could include analyzing DFX stakeholders' saliences in product development project teams. Further research is needed to develop a method to define required salience in the early phase of product development i.e. how to weight stakeholders of a project. Further research and development could include also improve AHP as a research tool. The improved AHP tool could analyze consistency of the answers instantly, give feedback to a respondent about consistency ratio and requesting revision of the answers if necessary.

\section{References}

[1] Ulrich, K.T. and Eppinger, S.D. (2008) Product Design and Development. 4th Edition, McGraw-Hill, New York.

[2] Bralla, J.G. (1996) Design for Excellence. McGraw-Hill, New York.

[3] Kuo, T.C., Huang, S.H. and Zhang, H.C. (2001) Design for Manufacture and Design for “X”: Concepts, Applications, and Perspectives. Computers and Industrial Engineering, 41, 241-260. http://dx.doi.org/10.1016/S0360-8352(01)00045-6

[4] Asiedu, Y. and Gu, P. (1998) Product Life Cycle Cost Analysis: State of the Art Review. International Journal of Production Research, 36, 883-908. http://dx.doi.org/10.1080/002075498193444

[5] Freeman, E.R. (1984) Strategic Management: A Stakeholder Approach. Pitman Publishing, Marshfield.

[6] Mitchell, R.K., Agle, B.R. and Wood, D.J. (1997) Toward a Theory of Stakeholder Identification and Salience: Defining the Principle of Who and What Really Counts. The Academy of Management Review, 22, 853-886.

[7] Olsen, J.R., Harmsen, H. and Friis, A. (2008) Linking Quality Goals and Product Development Competences. Food Quality and Preference, 19, 33-42. http://dx.doi.org/10.1016/j.foodqual.2007.06.002

[8] Cooper, R.G. and Kleinschmidt, E.J. (2007) Winning Businesses in Product Development: The Critical Success Factors. Research Technology Management, 50, 52-66.

[9] Olander, S. (2007) Stakeholder Impact Analyzis in Construction Project Management. Construction Management and Economics, 25, 277-287. http://dx.doi.org/10.1080/01446190600879125

[10] Meerkam, H. and Koch, M. (2004) Design for X. In: Clarkson, J. and Eckert, C., Eds., Design Process Improvement: A Review of Current Practice, Springer, New York.

[11] Huang, G.Q. (1996) Implementing Design for X Tools. In: Huang, G.Q., Ed., Design for X: Concurrent Engineering Imperatives, Chapman \& Hall, London.

[12] Lehto, J., Harkonen, J., Haapasalo, H., Belt, P., Mottonen, M. and Kuvaja, P. (2011) Benefits of DfX in Requirements Engineering. Technology and Investment, 2, 27-37. http://dx.doi.org/10.4236/ti.2011.21004

[13] Aaltonen, K. and Kujala, J. (2010) A Project Lifecycle Perspective on Stakeholder Influence Strategies in Global Projects. Scandinavian Journal of Management, 26, 381-397. http://dx.doi.org/10.1016/j.scaman.2010.09.001

[14] Aapaoja, A., Haapasalo, H. and Soderstrom, P. (2013) Early Stakeholder Involvement in the Project Definition Phase: Case Renovation. ISRN Industrial Engineering, 2013, Article ID: 953915.

[15] Olander, S. (2007) Stakeholder Impact Analysis in Construction Project Management. Construction Management and Economics, 25, 277-287. http://dx.doi.org/10.1080/01446190600879125

[16] Olander, S. and Landin, A. (2005) Evaluation of Stakeholder Influence in the Implementation of Construction Projects. International Journal of Project Management, 23, 321-328. http://dx.doi.org/10.1016/j.ijproman.2005.02.002

[17] IFC (2007) Stakeholder Engagement: A Good Practice Handbook for Companies Doing Business in Emerging Markets. IFC, Washington DC.

[18] Aaltonen, K., Kujala, J. and Oijala, T. (2008) Stakeholder Salience in Global Projects. International Journal of Project 
Management, 26, 509-516. http://dx.doi.org/10.1016/j.ijproman.2008.05.004

[19] Etzioni, A. (1964) Modern Organizations. Prentice Hall, Englewood Cliffs.

[20] Suchman, M.C. (1995) Managing Legitimacy: Strategic and Institutional Approaches. Academy of Management Review, 20, 571-610.

[21] Dowlatshahi, S. (1996) The Role of Logistics in Concurrent Engineering. International Journal of Production Economics, 44, 189-199. http://dx.doi.org/10.1016/0925-5273(96)00173-9

[22] Chiu, M.C. and Kremer, G.E.O. (2011) Investigation of the Applicability of Design for X Tools during Design Concept Evolution: A Literature Review. International Journal of Product Development, 13, 132-167. http://dx.doi.org/10.1504/IJPD.2011.038869

[23] Boothroyd, G., Dewhurst, P. and Knight, W. (1994) Product Design for Manufacture and Assembly. Illustration Edition, Marcel Dekker, New York.

[24] Macedo, I.S.M., Sousa-Gallagher, M.J., Oliveira, J.C. and Byrne, E.P. (2013) Quality by Design for Packaging of Granola Breakfast Product. Food Control, 29, 438-443. http://dx.doi.org/10.1016/j.foodcont.2012.05.045

[25] Dainty, A.R.J., Millett, S.J. and Briscoe, G.H. (2001) New Perspectives on Construction Supply Chain Integration. Supply Chain Management: An International Journal, 6, 163-173. http://dx.doi.org/10.1108/13598540110402700

[26] Yin, R.K. (1989) Case Study Research: Design and Methods. Sage Publications, Newbury Park.

[27] Saaty, T.L. (1980) The Analytic Hierarchy Process: Planning, Priority Setting, Resource Allocation. McGraw-Hill, New York.

[28] Al-Subhi Al-Harbi, K.M. (2001) Application of the AHP in Project Management. International Journal of Project Management, 19, 19-27. http://dx.doi.org/10.1016/S0263-7863(99)00038-1

[29] Agle, B.R., Mitchell, R.K. and Sonnenfeld, J.A. (1999) Who Matters to CEOs? An Investigation of Stakeholder Attributes and Salience, Corporate Performance, and CEO Values. Academy of Management Journal, 42, 507-525. http://dx.doi.org/10.2307/256973

[30] Cheng, E.W.L. and Li, H. (2003) Utility of Consistency Measure in the Analytic Hierarchy Process. Construction Innovation: Information, Process, Management, 3, 231-247.

[31] Aapaoja, A., Kinnunen, T. and Haapasalo, H. (2014) Stakeholder Salience Assessment for Construction Project Initiation. International Journal of Performance Measurement, in Press.

[32] Majava, J., Nuottila, J., Haapasalo, H. and Law, K.M.Y. (2014) Customer Needs in Market-Driven Product Development: Product Management and R\&D Standpoints. Technology and Investment, 5, 16-25. http://dx.doi.org/10.4236/ti.2014.51003

[33] Kropsu-Vehkapera, H., Haapasalo, H., Jaaskelainen, O. and Phusavat, K. (2011) Product Configuration Management in ICT Companies: The Practitioners’ Perspective. Technology and Investment, 2, 273-285.

http://dx.doi.org/10.4236/ti.2011.24028 